\title{
Balloon Catheter Nominal Inflation Pressure
}

National Cancer Institute

\section{Source}

National Cancer Institute. Balloon Catheter Nominal Inflation Pressure. NCI Thesaurus.

Code C150147.

Balloon pressure at balloon nominal diameter condition. 